\title{
Synthesis and optimization of 2-ethylhexyl ester as base oil for drilling fluid formulation
}

\begin{abstract}
A stable ester was synthesized to overcome the ester hydrolysis problem during the drilling of oil or gas wells using a conventional ester-based drilling fluid. The thermal and hydrolytic stability of the produced ester was high owing to the transesterification method employed in this study. The reaction was performed using 2-ethylhexanol and methyl laureate esters in the presence of sodium methoxide as a catalyst. In order to obtain the optimum synthesis conditions, a response surface methodology (RSM) was appraised based on the central composite design (CCD). The optimum conditions were determined as follows: $0.6 \mathrm{wt} \%$ catalyst, $70^{\circ} \mathrm{C}$ reaction temperature, $1: 1.5$ molar ratio, and $11.5 \mathrm{~min}$ of reaction time. The results of 77 wt.\% 2-ethylhexyl ester (2-EH) illustrated a high agreement between the experimental and RSM models. The reaction product contained $77 \mathrm{wt} \%$ 2-EH and 23\% 2ethylhexanol. The kinematic viscosity was $5 \mathrm{~mm} 2 / \mathrm{s}$ at $40^{\circ} \mathrm{C}$ and $1.5 \mathrm{~mm} 2 / \mathrm{sec}$ at $100^{\circ} \mathrm{C}$; the specific gravity was 0.854 , flash point was $170^{\circ} \mathrm{C}$, and pour point was $\overline{1} 7^{\circ} \mathrm{C}$. The produced product showed similar properties to the available commercial product. However, it was observed that the mud formulation using the synthesized base oil had superior rheological properties at $121^{\circ} \mathrm{C}$.
\end{abstract}

Keyword: 2-ethylhexonal ester; Drilling fluid formulation; Methyl laureate ester; Response surface methodology (RSM); Rheology; Transesterification 